\title{
Prevalence of hyperthyroidism with hypercalcemia in Xindu district and the efficacy of vitamin D3 treatment in these patients: a randomized trial
}

\author{
Xi Mei ${ }^{1}$, Jun Zeng ${ }^{2}$, Wen-Xue Dai ${ }^{2}$, Hui-Lan Yang ${ }^{1}$, Yao Li ${ }^{1}$, Ming-Wei Tang ${ }^{1}$, Ping Qiu ${ }^{1}$ \\ ${ }^{1}$ Department of Endocrinology, The First Affiliated Hospital of Chengdu Medical College, Xindu District, Chengdu, China; ${ }^{2}$ Journal Editorial \\ Office, Chengdu Medical College, Xindu District, Chengdu, China \\ Contributions: (I) Conception and design: X Mei; (II) Administrative support: None; (III) Provision of study materials or patients: X Mei, HL Yang, \\ Y Li, MW Tang, P Qiu; (IV) Collection and assembly of data: X Mei; (V) Data analysis and interpretation: J Zeng; (VI) Manuscript writing: All \\ authors; (VII) Final approval of manuscript: All authors. \\ Correspondence to: Jun Zeng. Chengdu Medical College, Chengdu, China. Email: 12671823@qq.com.
}

Background: This trial aimed to analyze the relationship between hyperthyroidism and the morbidity rate of hypercalcemia in the Xindu district, Chengdu, Sichuan province. We observed the level of serum calcium, the bone metabolic and thyroid autoimmune-related antibodies index during vitamin D3 treatment combined with traditional antithyroid drugs (ATD).

Methods: Our research included hyperthyroid patients with a first-time diagnosis of Graves diseases (GD) combined with hypercalcemia on the basis of conventional anti-hyperthyroidism therapy, which were randomized into a vitamin D3 group (vitamin D3, 800-1,200 IU/day) and an ATD group (methimazole, 15-30 mg/day). All hyperthyroidism patients with hypercalcemia were analyzed, and changes in serum calcium $\left(\mathrm{Ca}^{2+}\right)$, parathyroid hormone (PTH), thyroid function, thyroid autoimmune-related antibodies, and 25-dihydroxyvitamin D (25-OHVit D) levels during treatment of thyrotoxicosis with added vitamin D3 were explored.

Results: In total, 184 patients with hyperthyroidism were observed, including 36 (19.57\%) patients associated with hypercalcemia, with an age of onset of $(56.39 \pm 5.80)$ years old. Twelve $(6.52 \%)$ of these 36 cases reported digestive symptoms as the first manifestation, and four $(2.17 \%)$ patients presented with a hypercalcemia crisis as the first manifestation. Serum $\mathrm{Ca}^{2+}$, free triiodothyronine $\left(\mathrm{FT}_{3}\right)$, free thyroxine $\left(\mathrm{FT}_{4}\right.$ ), and thyrotropin hormone receptor antibody (TRAb) levels increased in patients with hypercalcemia. Following the addition of vitamin D3 treatment, serum $\mathrm{Ca}^{2+}, \mathrm{FT}_{3}, \mathrm{FT}_{4}$, and TRAb levels were significantly decreased relative to the ATD group, while the thyroid-stimulating hormone (TSH), PTH, and 25-OHVit D levels were normalized.

Conclusions: Our study highlighted the importance of taking functional digestive disturbance into consideration in hyperthyroidism diagnosis, even in the absence of the typical symptoms. The level of thyroid related antibodies, thyroid function, and bone metabolism in hyperthyroidism patients combined with hypercalcemia could be improved by vitamin D3 adjuvant therapy.

Trial Registration: Chinese Clinical Trial Registry: ChiCTR2 100047870.

Keywords: Hyperthyroidism; hypercalcemia; morbidity; vitamin D3; thyroid related antibodies

Submitted Jul 01, 2021. Accepted for publication Aug 27, 2021.

doi: 10.21037/apm-21-1947

View this article at: https://dx.doi.org/10.21037/apm-21-1947 


\section{Introduction}

Hyperthyroidism is typically characterized by symptoms such as irritability, sweating, palpitations without heart disease, weight loss despite good appetite, and goiter. Hyperthyroidism with electrolyte disturbance is the common clinical manifestation; however, Graves diseases (GD) accompanied by hypercalcemia is rarely observed, with a clinical incidence of $15-20 \%$ (1). However, changes in the levels of blood calcium or 25-hydroxyvitamin D (25-OHVit D) during the management of thyrotoxicosis remain unclear. Also, it is difficult to provide an adequate diagnosis and treatment of hypercalcemia patients due to the problem of excluding other causes. One reason is that hypercalcemia is caused by thyrotoxicosis, presumably due to the high levels of thyroid hormone leading to an increase in bone turnover $(2,3)$.

In this study, we observed the dynamic changes in serum calcium $\left(\mathrm{Ca}^{2+}\right)$ concentration relative to thyrotropin hormone receptor antibody (TRAb) and 25-OHVit D levels in hyperthyroidism patients during the course of conventional antithyroid oral medication therapy with the addition of vitamin D3. The effect of supplemental vitamin D3 on hypercalcemia in GD has not previously been investigated. Thus, we aimed to investigate whether vitamin D3 supplementation improves the recovery of serum $\mathrm{Ca}^{2+}$ and digestive disturbance symptoms in GD, and also describe the changes in these outcomes in response to antithyroid drugs (ATD).

GD is a multifactorial autoimmune thyroid disease (AITD) that is caused by the complex interaction of environmental and genetic factors. Typical signs and symptoms of hyperthyroidism include hyperhidrosis, tremor, palpitations, or tachycardia; however, symptoms of hypercalcemia rarely occur as the initial manifestations in hyperthyroidism. Hyperthyroidism leads to hypercalcemia due to bone calcium mobilization into the blood and increased levels of blood calcium.

Recent studies have found that vitamin $\mathrm{D}$ has an established association with different kinds of autoimmune diseases, and has been demonstrated to be a modulator of innate and adaptive immunity (4). Furthermore, it has been observed that supplementation with vitamin $\mathrm{D}$ can prevent the onset and/or development of various autoimmune disorders in human beings and animal models (5).

Thus, our study aimed to analyze the relationship between hyperthyroidism and the morbidity rate of hypercalcemia in the Xindu district, Chengdu, Sichuan province. We observed the level of serum calcium and the bone metabolic index during treatment with vitamin D3 combined with traditional ATDs. Furthermore, we also investigated the morbidity rate of hypercalcemia with the first manifestations of gastrointestinal symptoms in hyperthyroidism patients, as well as the correlation between vitamin D3 treatment of hyperthyroidism and hypercalcemia. Project research design scheme as shown in Figure 1.

We present the following article in accordance with the CONSORT reporting checklist (available at https://dx.doi. org/10.21037/apm-21-1947).

\section{Methods}

\section{Research subjects}

All participants were informed and provided written informed consent. This study was performed in accordance with the Declaration of Helsinki (as revised in 2013), and was approved by the committee on Chengdu Medical College Ethics (No.: 2021CYFYIRB-BA-21-01). This study was a randomized, single-blinded (All the patients were blinded during the trial), parallel group trial on the effects of 12 months of vitamin D3 versus non-added vitamin D3 given as a supplement to ATD treatment to newly diagnosed GD patients combined with hypercalcemia. Patients diagnosed at the Endocrine Outpatient Clinic and Inpatient Department of the First Affiliated Hospital, Chengdu Medical College from December 2019 to December 2020 were recruited, and follow-up was completed by June 2021 . All hyperthyroidism patients were diagnosed via thyroid function and thyrotropin hormone receptor antibody (TRAb) tests, and had complete medical history and clinical data. The primary endpoints were to observe the prevalence of hypercalcemia in patients with hyperthyroidism and the changes of thyroid autoimmune-related antibody indexes after intervention therapy with vitamin D3 supplementation. Secondary endpoints were changes in blood calcium, bone markers and bone mineral density. Hyperthyroidism was defined as thyroid-stimulating hormone (TSH) levels below the lower limit of the reference range $(0.56-5.91 \mathrm{mIU} / \mathrm{L})$ and total or free levels of free triiodothyronine $\left(\mathrm{FT}_{3}\right)$ and free thyroxine $\left(\mathrm{FT}_{4}\right)$ above the upper limit of the normal range ( $\mathrm{FT}_{3} 3.53-7.37 \mathrm{pmol} / \mathrm{L}$; FT4 7.98-16.02 pmol/L), as well as elevated levels of TRAb (normal range $\leq 1.75 \mathrm{IU} / \mathrm{L}$ ). Hypercalcemia was defined as serum $\mathrm{Ca}^{2+}>2.52 \mathrm{mmol} / \mathrm{L}$ (normal range 2.11-2.52 pmol/L). 


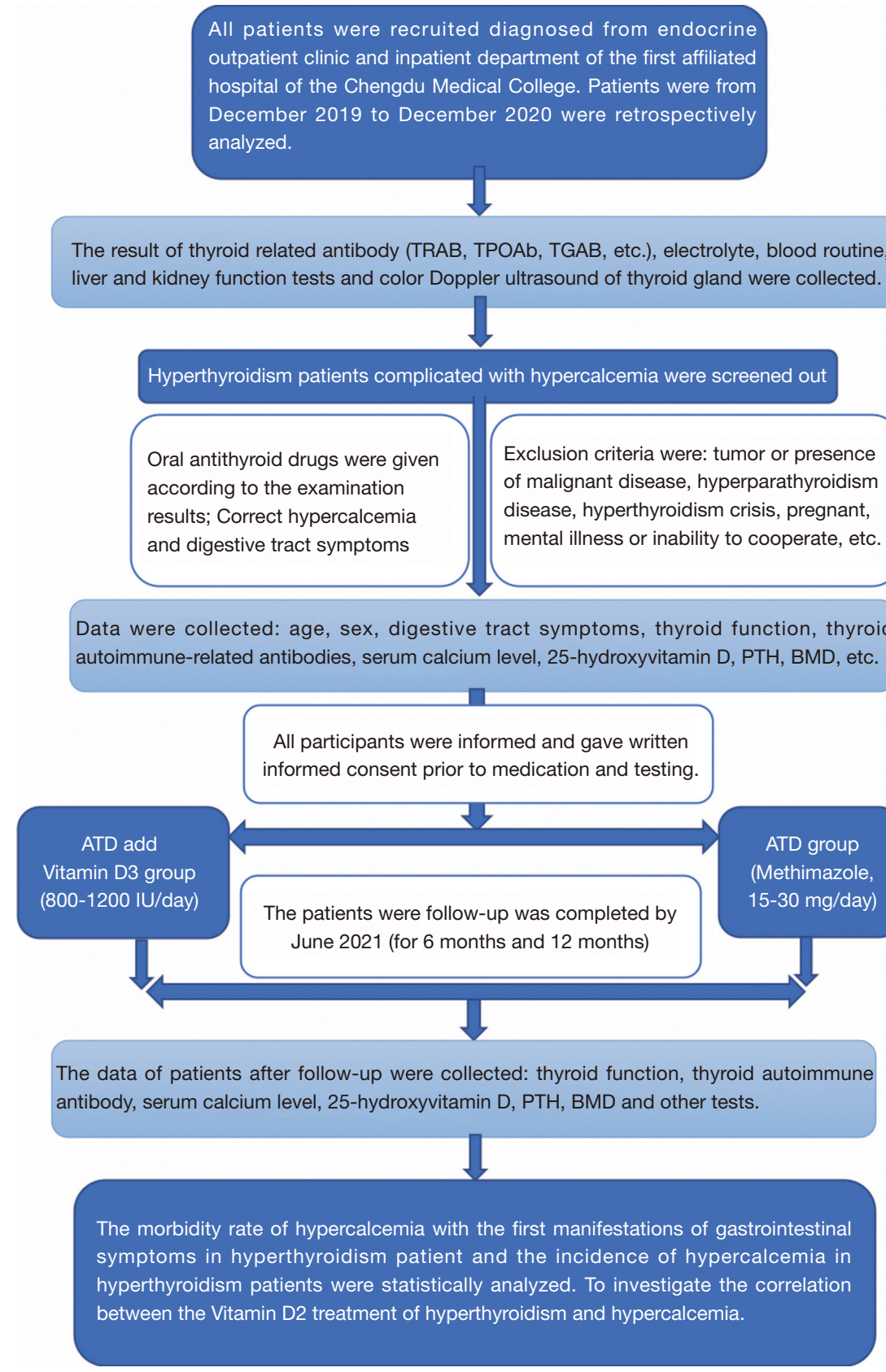

Figure 1 The project research design scheme.

The inclusion criteria were as follows: (I) patients aged between 18 and 70 years; (II) first-time diagnosis of GD; (III) hyperthyroidism combined with hypercalcemia at the first visit; and (IV) initiated or planned ATD as the treatment of choice. The exclusion criteria were as follows: (I) patients with non-hyperthyroidism disease or previous hyperthyroidism; (II) patients with serum $\mathrm{Ca}^{2+}$
$<2.52 \mathrm{mmol} / \mathrm{L}$ or impaired kidney function [estimated glomerular filtration rate (eGFR) $<45 \mathrm{~mL} / \mathrm{min}]$ (III) patients with tumor or presence of malignant disease; (IV) patients with hyperparathyroidism disease; (V) patients with hyperthyroidism crisis; (VI) patients with diabetes insipidus; (VII) those who were pregnant; and (VIII) patients with mental illness or an inability to cooperate. 
Table 1 Basic information of the two groups of patients

\begin{tabular}{lccc}
\hline \multirow{2}{*}{ Groups } & Age & Male & Female \\
\cline { 3 - 4 } & & 7 & 11 \\
Vitamin D group & $56.00 \pm 6.02$ & 8 & 10 \\
ATD group & $56.78 \pm 5.91$ & & \\
P value & 0.786 & & \\
\hline
\end{tabular}

There were no significant differences in the basic information of the two groups $(P>0.05)$. ATD, antithyroid drug.

During the study period, based on the description of exclusions and dropouts described above, 184 newly diagnosed GD patients were screened. In summary, 36 participants were included in the study and randomized (allocation ratio in this trial is 1:1) into a vitamin D3 group (Vitamin D3 800-1,200 IU/day, n=18) and an ATD group (methimazole $15-30 \mathrm{mg} /$ day, $\mathrm{n}=18$ ). The basic information of the two groups of patients is shown in Table 1. All hyperthyroidism patients with hypercalcemia were analyzed, and changes in the levels of serum $\mathrm{Ca}^{2+}$, parathyroid hormone (PTH), thyroid function, thyroid autoimmunerelated antibodies [including TRAb, thyroid peroxidase antibody (TPOAb), and thyroglobulin antibody (TGAb)], and 25-OHVit D during treatment of thyrotoxicosis with added vitamin D3 were investigated.

\section{Drugs and clinical test kit}

Vitamin D3 Soft Capsules (400 $\mu \mathrm{g} / \mathrm{pill})$ were purchased from Sinopharm Holding Star Shark Pharmaceutical (Xiamen) Co. Ltd, China, and thiamazole tablets $(10 \mathrm{mg} / \mathrm{tablet})$ were obtained from Merck KGaA, Germany. Assays for thyroid function (including TSH, $\mathrm{FT}_{3}$, and $\mathrm{FT}_{4}$ ) and all other biochemical measurements were performed at the clinical laboratory of the First Affiliated Hospital of the Chengdu Medical College (Beckman Coulter, Inc., USA). Bone mineral density (BMD) was measured using GE Dual X-ray Bone Density Tester (LUANR iDXA, GE Corporation of USA). The plasma levels of PTH (Abnova, Walnut, CA, USA; normal range, $10-65 \mathrm{pg} / \mathrm{mL}$ ) and 25-OHVit $\mathrm{D}$ [including $\mathrm{D}_{2}$ and $\mathrm{D}_{3}$; Guangzhou Jinqirui Biological Technology Co. Ltd, China; normal range, adults ( $>14$ years old): $<50 \mathrm{nmol} / \mathrm{L}$ (equivalent to $<20 \mathrm{ng} / \mathrm{mL}$ ): vitamin $\mathrm{D}$ deficiency, $50.0-75.0 \mathrm{nmol} / \mathrm{L}$ (equivalent to 20-30 ng/mL): vitamin D deficiency, 75-250 nmol/L (equivalent to $30-100 \mathrm{ng} / \mathrm{mL}$ ): normal vitamin $\mathrm{D},>250$ $\mathrm{nmol} / \mathrm{L}$ (equivalent to $>100 \mathrm{ng} / \mathrm{mL}$ ): vitamin $\mathrm{D}$ overdose] were measured by electrochemiluminescence immunoassay using the Cobas 6000 analyzer (Roche, USA).

\section{Statistical analyses}

All collected data were included in the statistical analysis. $\mathrm{P}$ values $<0.05$ were considered significant. Data were analyzed using SPASS 23.0 software (SPSS; Chicago, IL, USA).

\section{Results}

\section{The incidence of hypercalcemia and calciotropic hormones}

Of the 184 patients with hyperthyroidism, from December 2019 to December 2020 were recruited, and follow-up was completed by June 2021, as shown in Figure 1 and Table 1, 36 patients were associated with hypercalcemia (accounting for $19.57 \%)$. Twelve $(6.52 \%)$ of these 36 cases reported digestive symptoms as the first manifestation, while four $(2.17 \%)$ presented with hypercalcemia crisis as the first manifestation. The serum $\mathrm{Ca}^{2+}$ of these four patients returned to normal after treatment with double rounds of phosphate and fluid. Following addition of vitamin D3 to the conventional anti-thyroidism drug therapy, the serum $\mathrm{Ca}^{2+}$ and PTH levels in the vitamin D3 group were significantly decreased compared to those in the ATD group $(\mathrm{P}<0.05)$, while the 25 -OHVit $\mathrm{D}$ concentrations in the vitamin $\mathrm{D} 3$ group increased to the normal range compared to those in the ATD group $(\mathrm{P}<0.05$, Table 2).

\section{The index of thyroid function and thyroid autoantibodies}

The $\mathrm{FT}_{3}$ and $\mathrm{FT}_{4}$ levels in the vitamin $\mathrm{D} 3$ group were significantly decreased compared with those in the ATD group $(\mathrm{P}<0.05)$, while the TSH and TRAb levels in the vitamin $\mathrm{D} 3$ group increased to the normal range compared to those in the ATD group $(\mathrm{P}<0.05$, Tables 3 and 4$)$. Furthermore, the 25-OHVit D and FT4 levels decreased in parallel (Figure 2); the serum 25-OHVit D levels of two groups were lower than the normal range, while the serum PTH levels were in the low-normal range but were not suppressed before anti-thyroid treatment (Figure 3).

Compared with ATD group, the level of PTH and 25-hydroxyvitamin D values increased to the high-normal range following addition of vitamin $\mathrm{D} 3$ to conventional oral anti-thyroid treatment, and the hypercalcemia was completely relieved (Figure 4). Also, compared to the ATD group, the serum $\mathrm{Ca}^{2+}$ and $\mathrm{FT}_{4}$ levels were decreased 
Table 2 Index of calciotropic hormones

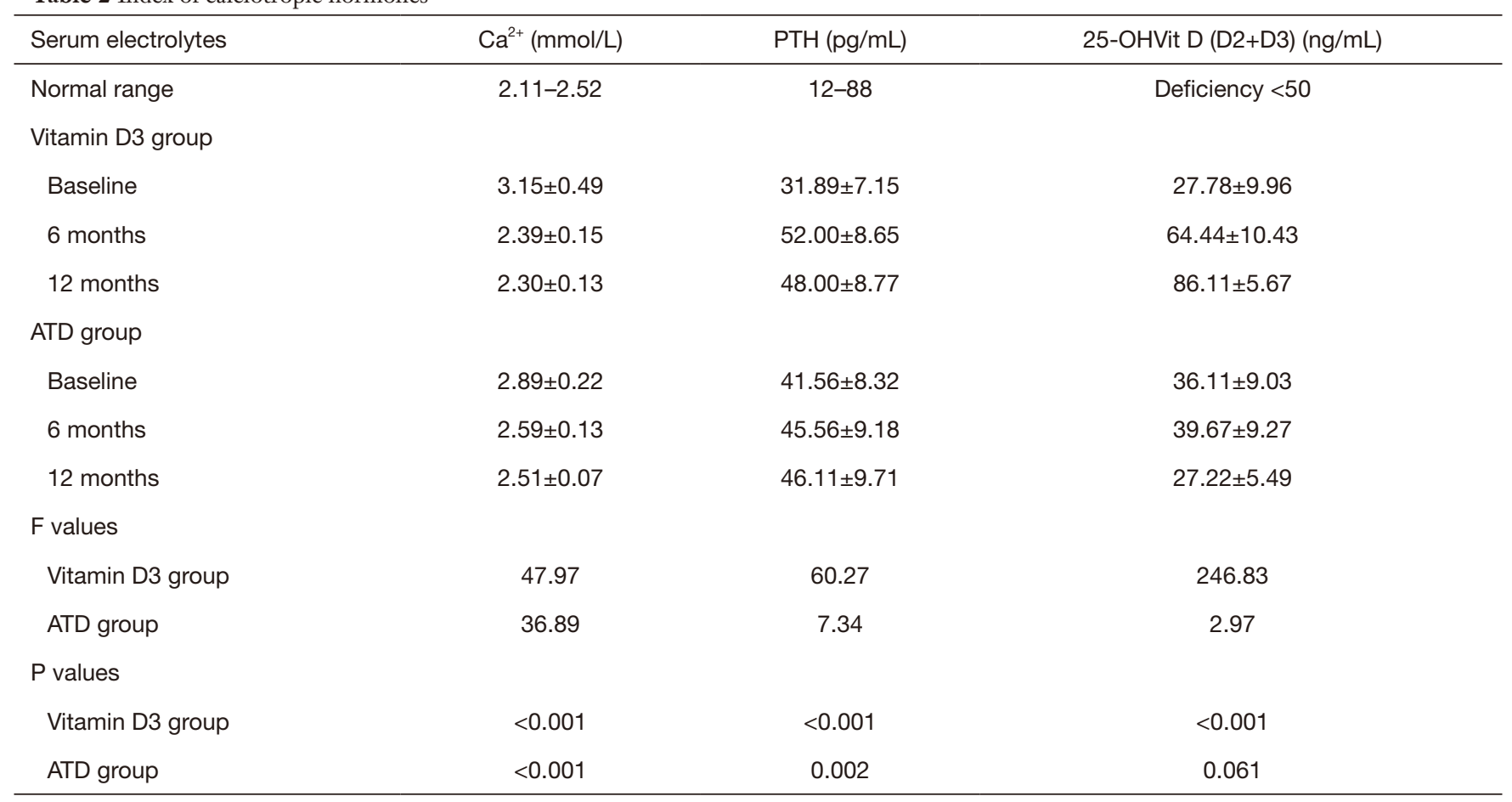

$P$ values were compared between the vitamin D3 and ATD groups at baseline, 6 months, and 12 months. 25-OHVit D, 25-hydroxyvitamin D; PTH, parathyroid hormone; ATD, antithyroid drug.

in parallel with the treatment of vitamin D3 added to oral anti-thyroid therapy, while the PTH, TRAb, and 25-hydroxyvitamin D concentrations were normalized.

\section{Bone mineral density (BMD)}

BMD was measured in the 36 GD patients with hypercalcemia. We found that the BMD index in vitamin D3 group were normalized with the addition vitamin D3 $(\mathrm{P}<0.05$, Table 5).

\section{Discussion}

In 1891, Von Recklinghausen first reported that hyperthyroidism initiated disorders in bone and mineral metabolism (6). However, in these cases, blood calcium rarely increases beyond $2.7 \mathrm{mmol} / \mathrm{L}$ (7). Although hypercalcemia is known to be one of the complications of thyrotoxicosis, its morbidity rate and pathogenesis remain unclear. Therefore, typical hypercalcemia symptoms rare occur. The reasons for hypercalcemia vary, and it could be divided into PTH dependency and non-PTH dependency (8). However, in our study, these results did not support hyperparathyroidism. Thus, we considered that the low level of PTH was induced by the significant increase of serum $\mathrm{Ca}^{2+}$, which gave negative feedback to PTH inhibition. Typically, the reason for non-PTH dependent hypercalcemia is malignant tumor, whose incidence rate ranks the second after hyperparathyroidism. Other reasons include multiple myeloma, vitamin A or D poisoning, glucocorticoids, renal disease, hyperthyroidism, and so on. In all cases in our study, the results did not support these diseases.

Previous studies have reported that the prevalence of hypercalcemia in patients with hyperthyroidism is $17-$ $50 \%(9,10)$. However, the truth of its prevalence may be difficult to evaluate. On one hand, many case reports have demonstrated that hypercalcemia may not be a common clinical manifestation that occurs in acute conditions of thyrotoxicosis (2), and thus might cause us to ignore testing for serum $\mathrm{Ca}^{2+}$ concentrations. On the other hand, many case reports also have described hyperthyroidism combined with other illnesses, such as tumor, renal insufficiency, or hyperparathyroidism (11-13). In our study, we observed a total of 134 patients with hyperthyroidism, 18 of whom were associated with hypercalcemia (accounting for $13.43 \%$ ). 
Table 3 Thyroid function results

\begin{tabular}{lccc}
\hline Thyroid function & $\mathrm{FT}_{3}(\mathrm{pmol} / \mathrm{L})$ & $\mathrm{FT}_{4}(\mathrm{pmol} / \mathrm{L})$ & $\mathrm{TSH}(\mathrm{IU} / \mathrm{L})$ \\
\hline Normal range & $3.53-7.37$ & $7.98-16.02$ & $0.56-5.91$ \\
Vitamin D3 group & & & \\
Baseline & $18.13 \pm 2.38$ & $54.89 \pm 8.24$ & $0.038 \pm 0.031$ \\
6 months & $6.70 \pm 0.47$ & $13.07 \pm 1.59$ & $0.91 \pm 0.61$ \\
12 months & $4.55 \pm 0.71$ & $10.98 \pm 2.27$ & $1.47 \pm 0.78$ \\
ATD group & & & \\
Baseline & $16.52 \pm 2.96$ & $47.61 \pm 8.08$ & $0.039 \pm 0.032$ \\
6 months & $6.89 \pm 0.19$ & $13.79 \pm 1.32$ & $0.65 \pm 0.42$ \\
12 months & $5.10 \pm 1.01$ & $10.44 \pm 2.09$ & $1.49 \pm 1.12$ \\
F values & & & \\
Vitamin D3 group & 508.39 & 431.22 & 55.28 \\
ATD group & 304.48 & 268.09 & 38.42 \\
P values & & & $<0.001$ \\
Vitamin D3 group & $<0.001$ & $<0.001$ & $<0.001$ \\
ATD group & $<0.001$ & $<0.001$ \\
\hline
\end{tabular}

$P$ values were compared between the vitamin D3 and ATD groups at baseline, 6 months, and 12 months. $\mathrm{FT}_{3}$, free triiodothyronine; $\mathrm{FT}_{4}$, free thyroxine; $\mathrm{TSH}$, thyroid-stimulating hormone; ATD, antithyroid drug.

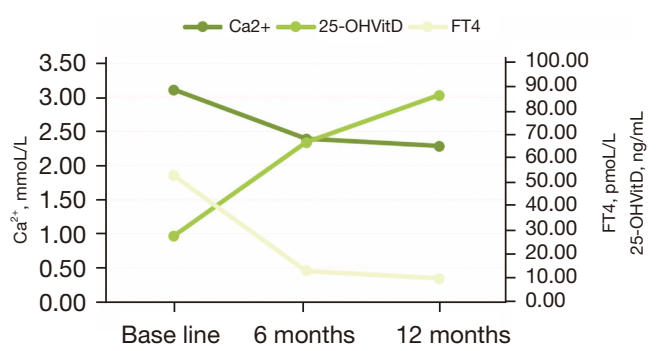

Figure 2 Relationship between 25-OHVit D and $\mathrm{FT}_{4}$ in the two groups. 25-OHVit D, 25-hydroxyvitamin $\mathrm{D} ; \mathrm{FT}_{4}$, free thyroxine.

Three $(2.23 \%)$ of these 18 cases reported digestive symptoms as the first manifestation, and two $(1.49 \%)$ of them presented with hypercalcemia crisis as the first manifestation. We also found that the majority (77\%) of these 18 patients were aged $50-65$ years or older, and these patients had varying degrees of low bone mass or osteoporosis.

Thyroid hormones have an important influence on bone turnover, and thus, we analyzed the BMD results of the 18 hyperthyroidism patients. Our study found that the average
Table 4 Data of thyroid autoantibodies

\begin{tabular}{lccc}
\hline $\begin{array}{l}\text { Anti-thyroid } \\
\text { antibody }\end{array}$ & $\begin{array}{c}\text { Anti-TPO } \\
(\mathrm{IU} / \mathrm{mL})\end{array}$ & $\begin{array}{c}\text { Anti-Tg } \\
(\mathrm{IU} / \mathrm{mL})\end{array}$ & $\begin{array}{c}\text { TRAb } \\
(\mathrm{IU} / \mathrm{L})\end{array}$ \\
\hline $\begin{array}{l}\text { Normal range } \\
\text { Vitamin D3 group }\end{array}$ & $0-34.0$ & $0-115$ & $0-1.75$ \\
Baseline & $66.04 \pm 23.38$ & $131.00 \pm 16.08$ & $5.94 \pm 1.57$ \\
6 months & $41.28 \pm 11.18$ & $66.72 \pm 7.76$ & $2.07 \pm 078$ \\
12 months & $8.49 \pm 3.36$ & $17.08 \pm 9.51$ & $1.09 \pm 0.15$ \\
ATD group & & & \\
Baseline & $65.10 \pm 18.73$ & $126.76 \pm 21.20$ & $5.92 \pm 1.20$ \\
6 months & $45.19 \pm 15.29$ & $88.77 \pm 9.85$ & $3.03 \pm 0.99$ \\
12 months & $35.92 \pm 8.79$ & $24.51 \pm 11.59$ & $1.79 \pm 0.31$ \\
F values & & & \\
Vitamin D3 group & 32.94 & 215.29 & 57.26 \\
ATD group & 9.07 & 105.98 & 47.99 \\
P values & & & $<0.001$ \\
Vitamin D3 group & $<0.001$ & $<0.001$ & $<0.001$ \\
ATD group & 0.001 & $<0.001$ & \\
\hline
\end{tabular}

$P$ values were compared between the vitamin D3 and ATD groups at baseline, 6 months, and 12 months. TRAb, thyrotropin hormone receptor antibody; ATD, antithyroid drug.

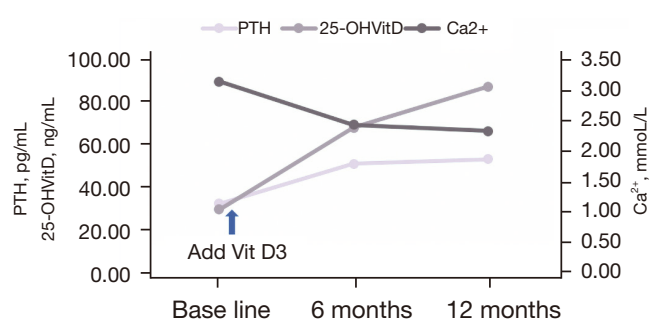

Figure 3 Relationship between 25-OHVit D, PTH, and serum $\mathrm{Ca}^{2+}$ in the two groups. 25-OHVit D, 25-hydroxyvitamin D; PTH, parathyroid hormone.

age of these 18 patients ranged from 56-65, including 12 females and six males, and the T-value of BMD detected was $-3.0 \pm-0.7$, with $72 \%$ of the patients being diagnosed with osteoporosis and $28 \%$ with bone loss. The reason for elevated blood calcium is that excessive thyroid hormones accelerate bone absorption, and bone calcium is mobilized to release into the bloodstream. We speculate that the reason why elderly patients with hyperthyroidism are prone to hypercalcemia may be that they have low bone mass or 


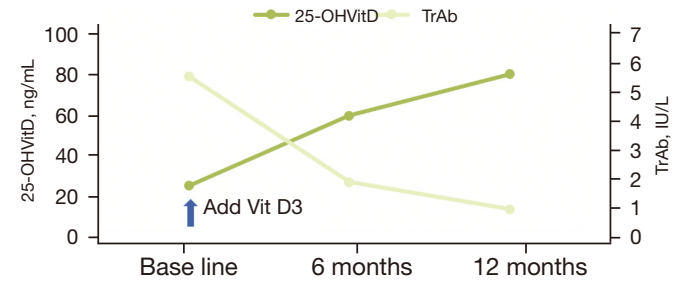

Figure 4 Relationship between 25-OHVit D and TRAb in the two groups. 25-OHVit D, 25-hydroxyvitamin D; TRAb, thyrotropin hormone receptor antibody.

osteoporosis, which accelerates calcium transfer from bone to blood.

Vitamin D drops are different from calcitriol in that each tablet contains vitamin D3 (400 IU/tablet). The use of common vitamin D3 increased the levels of 25-OHVit $\mathrm{D}$ and $25-(\mathrm{OH})_{2} \mathrm{VitD}_{3}$ in the blood, and the latter had sufficient levels to promote intestinal calcium transport, which could effectively mobilize blood calcium, promote bone formation, and increase bone mineralization. In addition, ordinary vitamin D3 was transformed into $1,25-(\mathrm{OH})_{2} \mathrm{VitD}_{3}$, with the highest activity after lightening of the liver and kidney, which stimulated osteoblasts to proliferate, differentiate, and promote bone formation (14). Recent research has indicated that the 1,25-OHVitD3 levels, like PTH, are not inhibited in all hyperthyroidism patients with hypercalcemia (15). In this study, we examined the relationship between hyperthyroidism, PTH, serum $\mathrm{Ca}^{2+}$ and 25-OHVit D levels. We observed that the changes in 25-OHVit D concentration were likely mediated by hypercalcemia and increased $\mathrm{FT}_{4}$ levels. Our study showed that the serum 25-OHVit D levels of both groups were lower than the normal range, while the serum PTH level was in the low-normal range, but was not suppressed before anti-thyroid treatment; this observation is consistent with the findings of other studies (16). We speculated that the low-normal PTH value may have been the result of attenuated adipose reserves of cholecalciferol after extensive weight loss caused by thyrotoxicosis, which could have led to decreased suppression of PTH. However, our results also showed that, compared with the ATD group, the level of $\mathrm{PTH}$ and 25-OHVit D values were increased to the highnormal range following addition of vitamin $\mathrm{D}$ to traditional oral anti-thyroid treatment, and the hypercalcemia were completely returned to normal levels.

Previous studies have indicated that the concomitant changes of bone resorption and bone formation may reflect the coupling nature of bone turnover, and the increase of bone turnover markers has been observed in patients with hyperthyroidism (17), and that this change may be directly correlated with serum $\mathrm{FT}_{4}$ levels (18). Our study showed that the serum $\mathrm{Ca}^{2+}$ and $\mathrm{FT}_{4}$ levels were decreased in parallel with the treatment of vitamin D3 added to oral antithyroid therapy, while the concentrations of PTH, TRAb, and 25-OHVit D were normalized. We hypothesized that the normalization of TPOAb, TGAb, and TRAb level may be related to the treatment of vitamin D3 supplementation in addition to traditional oral ATD. However, the specific mechanism of its influence is still unclear and requires further research.

In addition, it is worth noting that our study also identified three cases of hyperthyroidism patients with hypercalcemia crisis as the first manifestation, such as repeated abdominal discomfort, nausea, and vomiting. After rehydration, diuresis, calcium reduction therapy, and the addition of vitamin D3 to hyperthyroidism treatment, the serum $\mathrm{Ca}^{2+}$ level could rapidly decrease or revert back to normal. It is known that hyperthyroidism can cause the osteoporosis: bone calcium is mobilized into the blood, thereby increasing blood calcium. Increased blood calcium may significantly increase the secretion of gastric acid. A possible mechanism is the calcium in advanced acetylcholine is released by synapse, which provokes gastric acid secretion by stomach cells via vagus nerve stimulation (19). Another possible mechanism is vagus nerve stimulating gastrin release, which leads to increased gastric acid secretion (20). However, hyperthyroidism control requires a certain period of time, which demands immediate treatment on hypercalcemia to prevent a hypercalcemia crisis $(21,22)$.

\section{Conclusions}

Our study highlights the importance of taking functional digestive disturbance into consideration in the diagnosis of hyperthyroidism, even in the absence of the typical symptoms. The level of thyroid function and bone metabolism in hyperthyroidism patients combined with hypercalcemia can be improved by vitamin D3 adjuvant therapy. However, our study was limited by the fact that the number of cases collected was small, and the observation time was short. Thus, collection and observation of more cases for further research is needed. Also, further investigation is required to determine the mechanisms by which thyrotoxicosis induces hypercalcemia and the effect of vitamin D3 supplementation on thyroid-associated 
Table 5 The result of BMD

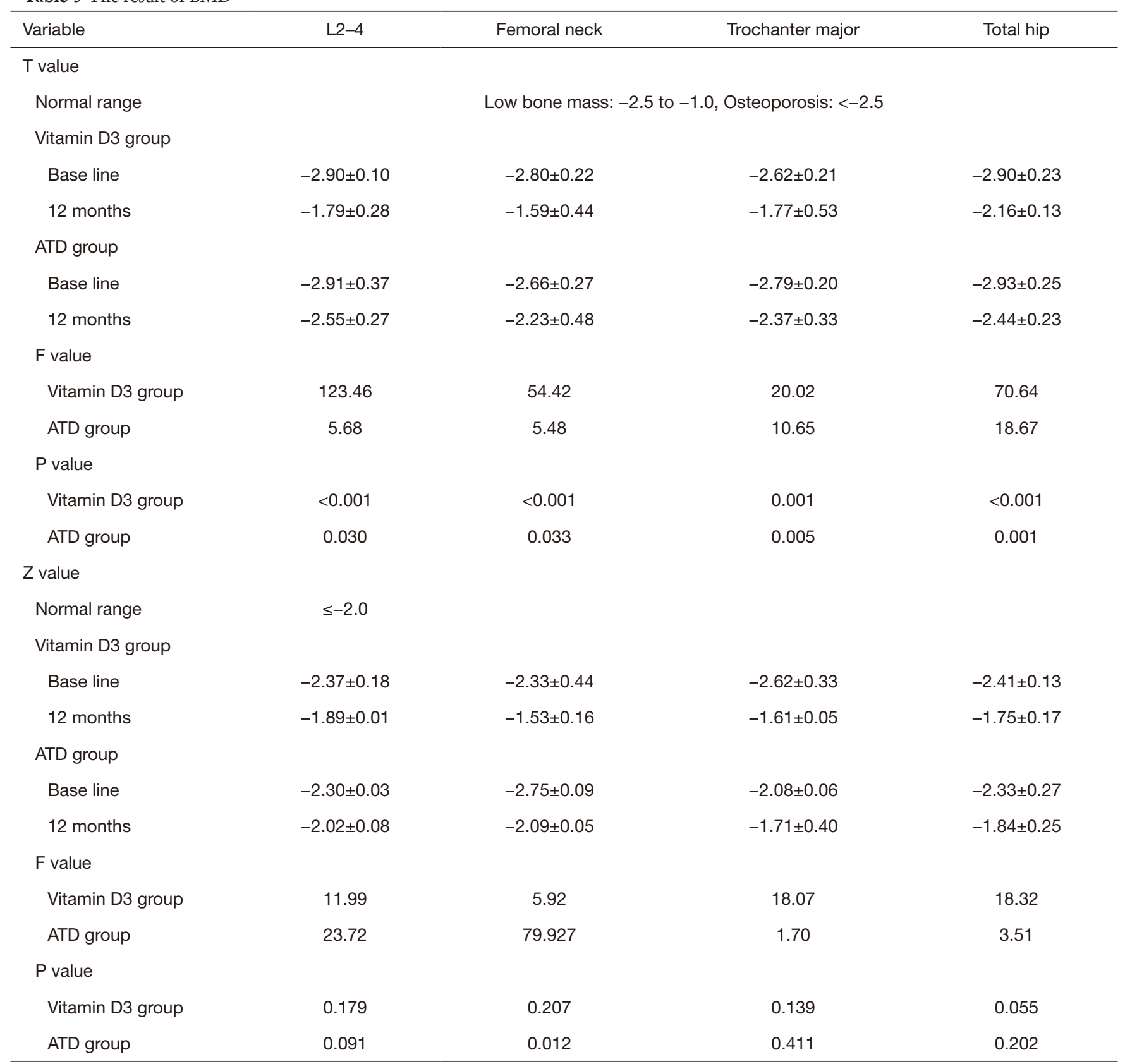

P values were compared between the vitamin D3 and ATD groups at baseline and 12 months. ATD, antithyroid drug; BMD, bone mineral density.

antibodies.

\section{Acknowledgments}

Funding: This study received the support from the Key Discipline Construction Project of Sichuan Province (2017, No. 62).

\section{Footnote}

Reporting Checklist: The authors have completed the CONSORT reporting checklist. Available at https://dx.doi. org/10.21037/apm-21-1947

Trial Protocol: Available at https://dx.doi.org/10.21037/apm21-1947 
Data Sharing Statement: Available at https://dx.doi. org/10.21037/apm-21-1947

Conflicts of Interest: All authors have completed the ICMJE uniform disclosure form (available at https://dx.doi. org/10.21037/apm-21-1947). The authors have no conflicts of interest to declare.

Ethical Statement: The authors are accountable for all aspects of the work in ensuring that questions related to the accuracy or integrity of any part of the work are appropriately investigated and resolved. This study was performed in accordance with the Declaration of Helsinki (as revised in 2013), and was approved by the committee on Chengdu Medical College Ethics (No.: 2021CYFYIRBBA-21-01). All participants were informed and provided written informed consent.

Open Access Statement: This is an Open Access article distributed in accordance with the Creative Commons Attribution-NonCommercial-NoDerivs 4.0 International License (CC BY-NC-ND 4.0), which permits the noncommercial replication and distribution of the article with the strict proviso that no changes or edits are made and the original work is properly cited (including links to both the formal publication through the relevant DOI and the license). See: https://creativecommons.org/licenses/by-nc-nd/4.0/.

\section{References}

1. Korytnaya E, Rao NG, Mayrin JV. An unusual case of hypercalcemia associated with graves' disease and vitamin d deficiency. Clin Med Insights Endocrinol Diabetes 2011;4:25-8.

2. Baxter JD, Bondy PK. Hypercalcemia of thyrotoxicosis. Ann Intern Med 1966;65:429-42.

3. Alikhan Z, Singh A. Hyperthyroidism manifested as hypercalcemia. South Med J 1996;89:997-8.

4. Wei R, Christakos S. Mechanisms Underlying the Regulation of Innate and Adaptive Immunity by Vitamin D. Nutrients 2015;7:8251-60.

5. Sheriba N, Elewa AA, Mahdy M, et al. Effect of vitamin D3 in treating hyperthyroidism in patients with graves' disease. The Egyptian Journal of Internal Medicine 2017;29:64.

6. Von Recklinghausen FC. Die fibrose oder deformierende ostitis, die osteomalazie und die osteoplastische karzinose in ihren gegenseitigen beziehungen. In: Festschrift
Rudolph Virchow. Berlin: G Reiner, 1891:1-89.

7. Daly JG, Greenwood RM, Himsworth RL. Serum calcium concentration in hyperthyroidism at diagnosis and after treatment. Clin Endocrinol (Oxf) 1983;19:397-404.

8. Silverberg SJ, Bilezikian JP. The diagnosis and management of asymptomatic primary hyperparathyroidism. Nat Clin Pract Endocrinol Metab 2006;2:494-503.

9. Hayes JR, Ritchie CM. Hypercalcaemia due to thyrotoxicosis. Ir J Med Sci 1983;152:422-3.

10. Hassan EE. Assessment of serum level of calcium and phosphorus in sudanese patients with hyperthyroidism. World Journal of Pharmacy and Pharmaceutical Sciences 2014;3:20-7.

11. Wada S, Kurihara S, Imamaki K, et al. Hypercalcemia accompanied by hypothalamic hypopituitarism, central diabetes inspidus and hyperthyroidism. Intern Med 1999;38:486-90.

12. Endo A, Shigemasa C, Kouchi T, et al. Development of hypercalcemic crisis in a Graves' hyperthyroid patient associated with central diabetes insipidus. Intern Med 1995;34:924-8.

13. Iqbal AA, Burgess EH, Gallina DL, et al. Hypercalcemia in hyperthyroidism: patterns of serum calcium, parathyroid hormone, and 1,25-dihydroxyvitamin D3 levels during management of thyrotoxicosis. Endocr Pract 2003;9:517-21.

14. Kim M, Song E, Oh HS, et al. Vitamin D deficiency affects thyroid autoimmunity and dysfunction in iodine-replete area: Korea national health and nutrition examination survey. Endocrine 2017;58:332-9.

15. Maestro MA, Molnár F, Carlberg C, et al. Vitamin $\mathrm{D}$ and Its Synthetic Analogs. J Med Chem 2019;62(15):6854-6875.

16. Mason RS, Lissner D, Wilkinson M, et al. Vitamin $\mathrm{D}$ metabolites and their relationship to azotaemic osteodystrophy. Clin Endocrinol (Oxf) 1980;13:375-85.

17. Suzuki T, Nakamura Y, Kato H. Vitamin D and Calcium Addition during Denosumab Therapy over a Period of Four Years Significantly Improves Lumbar Bone Mineral Density in Japanese Osteoporosis Patients. Nutrients 2018;10:272.

18. Reddy PA, Harinarayan CV, Sachan A, et al. Bone disease in thyrotoxicosis. Indian J Med Res 2012;135:277-86.

19. Owen JL, Cheng SX, Ge Y, et al. The role of the calciumsensing receptor in gastrointestinal inflammation. Semin Cell Dev Biol 2016;49:44-51.

20. Hannan FM, Kallay E, Chang W, et al. The calciumsensing receptor in physiology and in calcitropic 
and noncalcitropic diseases. Nat Rev Endocrinol 2018;15:33-51.

21. Chen K, Xie Y, Zhao L, et al. Hyperthyroidism-associated hypercalcemic crisis: A case report and review of the literature. Medicine (Baltimore) 2017;96:e6017.

Cite this article as: Mei X, Zeng J, Dai WX, Yang HL, Li Y, Tang MW, Qiu P. Prevalence of hyperthyroidism with hypercalcemia in Xindu district and the efficacy of vitamin D3 treatment in these patients: a randomized trial. Ann Palliat Med 2021;10(9):9640-9649. doi: 10.21037/apm-21-1947
22. Williams GR, Bassett JHD. Thyroid diseases and bone health. J Endocrinol Invest 2018;41:99-109.

(English Language Editor: A. Kassem) 